\title{
Evaluation of sternal morphology according to age and sex with multidetector computerized tomography
}

\author{
Güneş Bolatlı ${ }^{1}$ (D), Nadire Ünver Doğan² (D), Mustafa Koplay ${ }^{3}$ (D), Zeliha Fazlıoğulları ${ }^{2}$ (D), \\ Ahmet Kağan Karabulut ${ }^{2}$ \\ ${ }^{1}$ Department of Anatomy, School of Medicine, Siirt University, Siirt, Turkey \\ ${ }^{2}$ Department of Anatomy, School of Medicine, Selçuk University Konya, Turkey \\ ${ }^{3}$ Department of Radiology, School of Medicine, Selçuk University, Konya, Turkey
}

\begin{abstract}
Objectives: The sternum is located in the middle of the anterior wall of the thoracic cage. It consists of three parts; manubrium, body (corpus) and xiphoid process. Since it is an easy bone to scan, it can be used for age and sex determination in forensic medicine. The aim of the study was to investigate the characteristics of the sternum according to age and gender.

Methods: This study was performed retrospectively on $700 \mathrm{CT}$ images. 3D volume rendering images of sternum were created from the axial CT images at a $1 \mathrm{~mm}$ slice thickness.

Results: There were significant differences in sternum measurements according to age and sex. The xiphoid process was identified under three different types. Ossification between the manubrium and sternum body showed significant differences according to age and sex.
\end{abstract}

Conclusion: Data collected from a single bone is important for age and sex prediction especially in forensic medicine. These data taken from a large series may also contribute to evaluation of variations in sternal morphology.

Keywords: anatomy; multidetector computerized tomography; morphology; sternum

Anatomy 2020;14(1):29-38 @2020 Turkish Society of Anatomy and Clinical Anatomy (TSACA)

\section{Introduction}

The sternum originates from a pair of vertical mesenchymal bands that develop ventrolaterally on the anterior wall of the body. These mesenchymal bands are called as sternal bands in which cartilage development occurs in the craniocaudal direction. Then, the cartilage gets ossified to form sternum. The manubrium and the xiphoid process ossifies from a single center whereas the body (mesosternum) from four centers. The ossification centers begin to form in the sixth intrauterine month and the ossification process continues during the first postnatal life. The development of xiphoid process is generally completed between $5-18$ years of age. ${ }^{[1]}$ The ossifica- tion centers of manubrium and body of sternum grow in the cephalocaudal direction and develop till 12 years of age. The ossification centers in the body of sternum develop in caudocephalic direction and complete between puberty and 25 years of age. ${ }^{[1]}$ Manubriosternal and sternoxiphoid ossification continues in adulthood. ${ }^{[2]}$

A variety of bones have been explored for gender prediction. ${ }^{[3-5]}$ The sternum is a strong bone that does't deform easily for a long time, therefore it can be used for age and gender prediction. ${ }^{[6]}$ Multidetector computerized tomography (MDCT) imaging method is gold standart to evaluate bone tissue hat easily provides a detailed imaging of the sternum. ${ }^{[7]} \mathrm{A}$ through knowledge of the

This study was presented as an oral presentation at 1st International Congress on Sports, Antbropology, Nutrition, Anatomy and Radiology/SANAR2018, 3-5 May 2018, Cappadocia, Nevşebir, Turkey. 
Table 1

Distribution of cases by age and gender.

\begin{tabular}{lcccccccc} 
Age & $\mathbf{0 - 9}$ & $\mathbf{1 0 - 1 9}$ & $\mathbf{2 0 - 2 9}$ & $\mathbf{3 0 - 3 9}$ & $\mathbf{4 0 - 4 9}$ & $\mathbf{5 0 - 5 9}$ & $\mathbf{2 6 0}$ & Total \\
\hline Female & 9 & 22 & 32 & 45 & 56 & 46 & 127 & 337 \\
Male & 16 & 25 & 41 & 53 & 41 & 45 & 142 & 363 \\
\hline
\end{tabular}

ossification, variations and morphological anatomy of the sternum is not only important for age and sex determination in forensic medicine but also for planning thoracic surgeries and decreasing postoperative complications. ${ }^{[8]}$ The aim of this study, therefore, was to evaluate the sternal morphology according to age and gender using MDCT on a large series to provide substantial data for forensic scientists and thoracic surgeons.

\section{Materials and Methods}

This study was conducted with the permission taken from the Selçuk University School of Medicine NonInterventional Clinical Research Ethics Committee (Approval number: 2017/69).

Thin section MDCT thoracal images of 897 patients were examined between January 2016 and May 2017. These patients had undergone CT imaging because of various reasons but none of them had any previous history of thoracic trauma or surgery. Images of 78 cases were excluded from the study due to interference in the region, and images of 119 cases due to low resolution. Thus, 700 images were included in the study. CT images obtained in an axial plane at a thickness of $1 \mathrm{~mm}$. In addition to axial images, sagittal and coronal reformat images were obtained at the workstation.

The images were grouped according to the gender and age. Accordingly, 7 different age groups were determined as: 0-9 years, 10-19 years, 20-29 years, 30-39 years, $40-49$ years, $50-60$ years, and $\geq 60$ years (Table 1 ).

The width and length of manubrium and body of sternum and the angle between the manubrium and the body (angle of Louis) were measured on sagittal and coronal images. Variations of the sternum were also examined in all sections.

The measurements were done as follows; Manubrium width (MW): the distance between the midpoint of the right and left first costal notches on coronal images (Figure 1); Manubrium length (ML): the distance between the jugular notch and the midpoint of the manubriosternal joint on coronal images (Figure 1); Corpus length (CL): the distance between the midpoint of the manubriosternal joint and the midpoint of the symphysis xiphosternal joint on coronal images (Figure 1); Corpus width (CW1): the horizontal distance measured between 2 nd and 3 rd costal notches on the coronal images (Figure 1); Corpus width (CW2): the horizontal distance measured between 4th and 5 th costal notches on the coronal images (Figure 1); Angle of Louis (LA): the angle between the manubrium and the body measured on sagittal images (Figure 2).

Xiphoid process was examined under three types according to its shape; Type 1: having two extensions; Type 2: in the form of a single extension; Type 3: having three extensions (Figure 3).

The sternum was examined under two types according to the direction of the xiphoid process; Type 1: xiphoid process having the same direction with the body of sternum; Type 2: xiphoid process having a slope towards the ventral direction (Figure 4). ${ }^{[7,9]}$

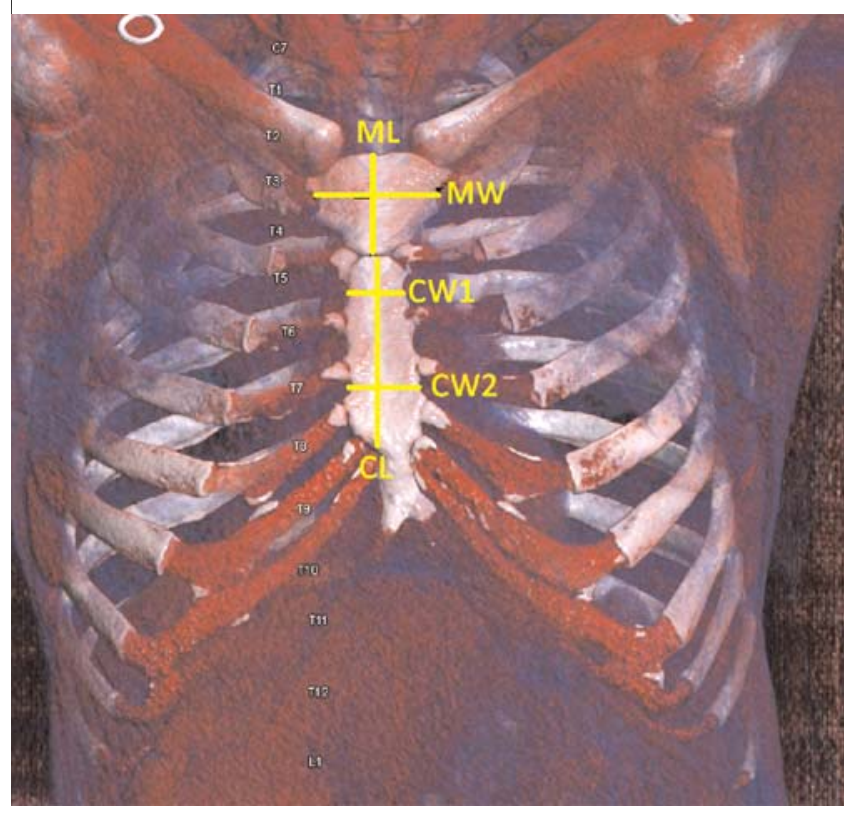

Figure 1. Measurements of the sternum done with multidetector computerized tomography. CL: corpus length; CW1: corpus width between 2nd and 3rd costal cartilages; CW2: corpus width between 3rd and 4th costal cartilages; ML: manubrium length; MW: manubrium width. 
The presence and number of foramen on the xiphoid process and corpus were also determined (Figure 5).

The ossification of the sternum was also examined and it is further classified under three types according to the amount of ossification; Type 1: no ossification; Type 2: partial ossification; and Type 3: complete of ossification (Type 3) (Figure 6).

The data obtained in the study were analyzed using SPSS (Statistical Package for Social Sciences) for Windows (version 22, Chicago, IL, USA). The data were expressed as number, percentage, mean \pm standard deviation (SD). The relationship between grouped variables was analyzed by chi-square analysis. The t-test and oneway ANOVA were used to compare the significance between different groups. Scheffe test was used as a complementary post-hoc analysis to determine the differences after the ANOVA test. Pearson correlation analysis was used for determining significant correlations. For all analyses, $\mathrm{p}<0.05$ was considered as statistically significant.

\section{Results}

The mean width of the manubrium (MW) was $5.13 \pm 0.93$ $\mathrm{cm}$. The $M W$ was significantly higher in males $(5.32 \mathrm{~cm})$ compared to females $(4.92 \mathrm{~cm})(\mathrm{p}<0.05)$. MW showed significant differences among age groups and genders $(p \leq 0.05)$. The $M W$ was significantly higher in $\geq 60$ and lower in the 0-9 age group for both genders. The MW was significantly lower in the $0-9$ and $10-19$ age groups compared to other age groups (Table 2).

The mean length of the manubrium (ML) was $4.54 \pm 0.73 \mathrm{~cm}$. The ML was significantly higher in males

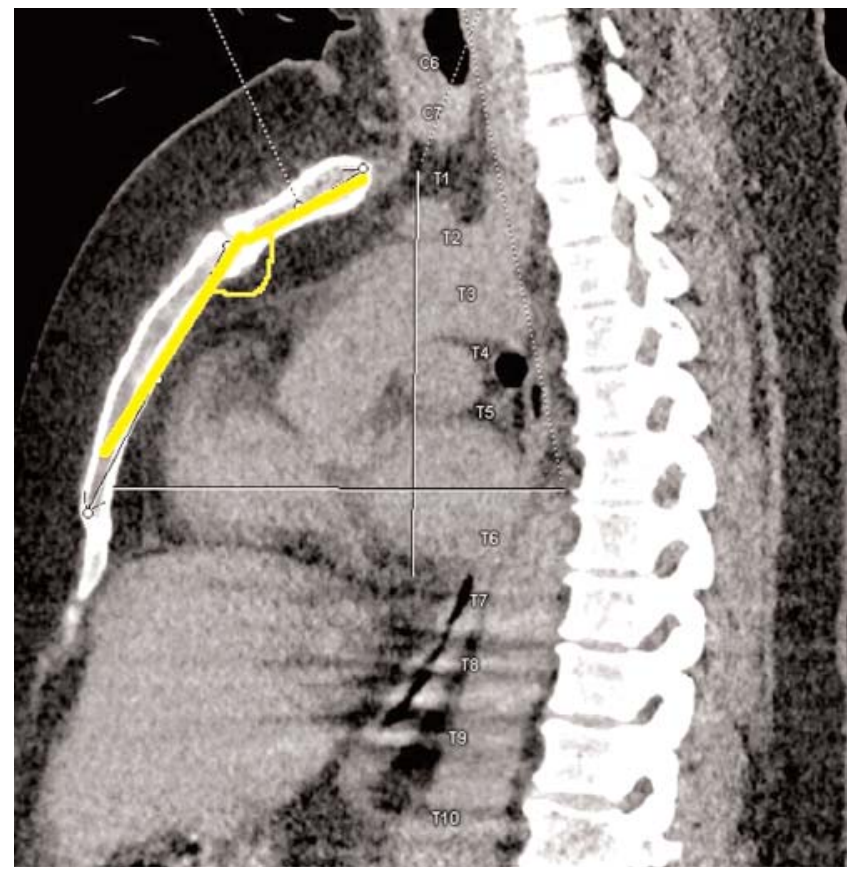

Figure 2. Measurement of angle of Louis with MDCT.

$(4.66 \mathrm{~cm})$ than females $(4.42 \mathrm{~cm})(\mathrm{p}<0.05)$. The $M L$ showed significant differences among age group and gen$\operatorname{der}(\mathrm{p}<0.05)$. The ML was significantly higher in $\geq 60$ and lower in the $0-9$ age group for both genders. The ML was significantly higher in 10-19 age group than the 0-9 age group. The ML values of other age groups were significantly higher than $0-9$ and $10-19$ age groups (Table 3).

The mean length of body of sternum (CL) was found to be $8.91 \pm 0.69 \mathrm{~cm}$ in males and $8.23 \mathrm{~cm}$ in females. The CL was significantly higher in males than females
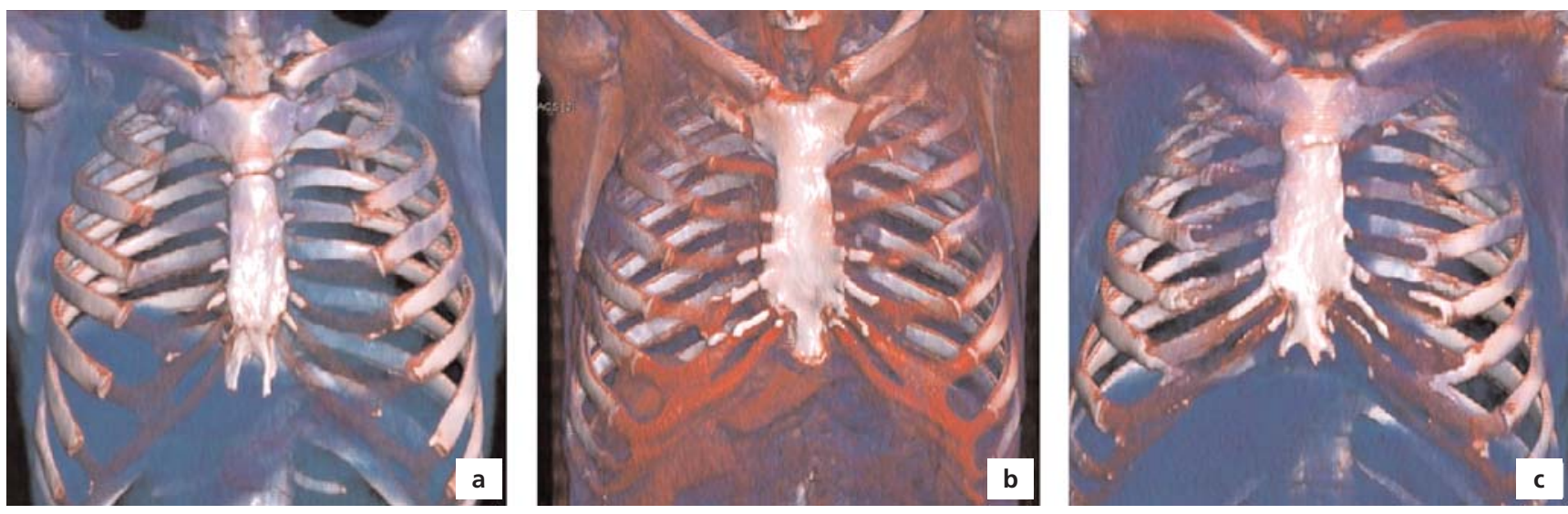

Figure 3. Types of the xiphoid process according to its shape. (a) Xiphoid process with 2 extensions (Type 1); (b) xiphoid process in the form of a single extension (Type 2); (c) xiphoid process with 3 extensions (Type 3). 

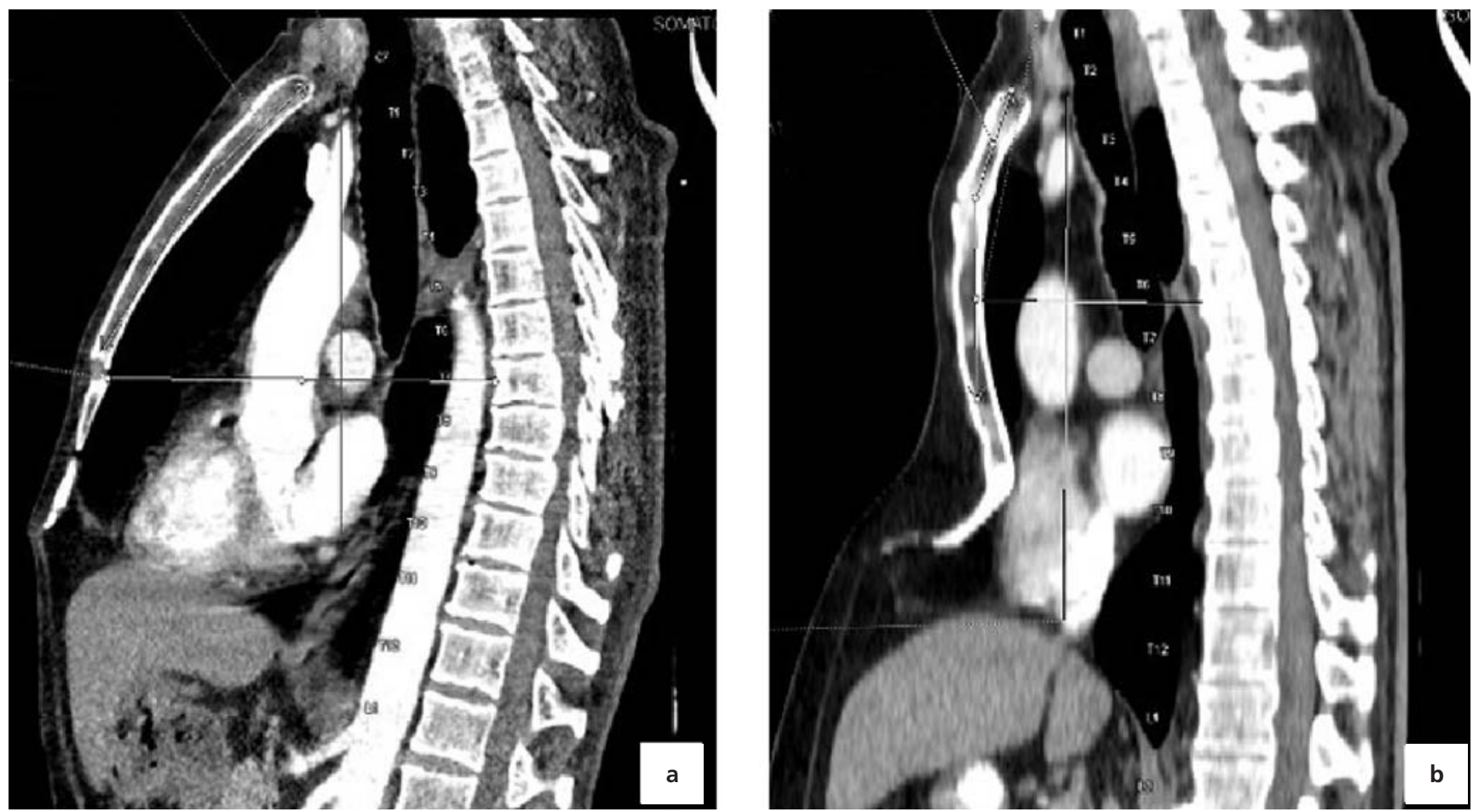

Figure 4. Types of xiphoid process according to its direction. (a) Xiphoid process in line with the body of sternum corpus; (b) xiphoid process having a slope towards the ventral direction.

$(\mathrm{p}<0.05)$. The CL was also significantly higher in $\geq 60$ and lower in the $0-9$ age group for both genders (Table 4).

The width of the corpus was measured by using two reference lines (CW1 and CW2). The mean CW1 was
$2.72 \pm 0.58 \mathrm{~cm}$, where as CW2 $3.23 \pm 0,76 \mathrm{~cm}$. The mean CW1 was significantly higher in males $(2.83 \mathrm{~cm})$ than females $(2.59 \mathrm{~cm})(\mathrm{p}<0.05)$ likewise the CW2 that is 3.47 $\mathrm{cm}$ in males and 3.1 in females $(\mathrm{p}<0.05)$. The CW1 and
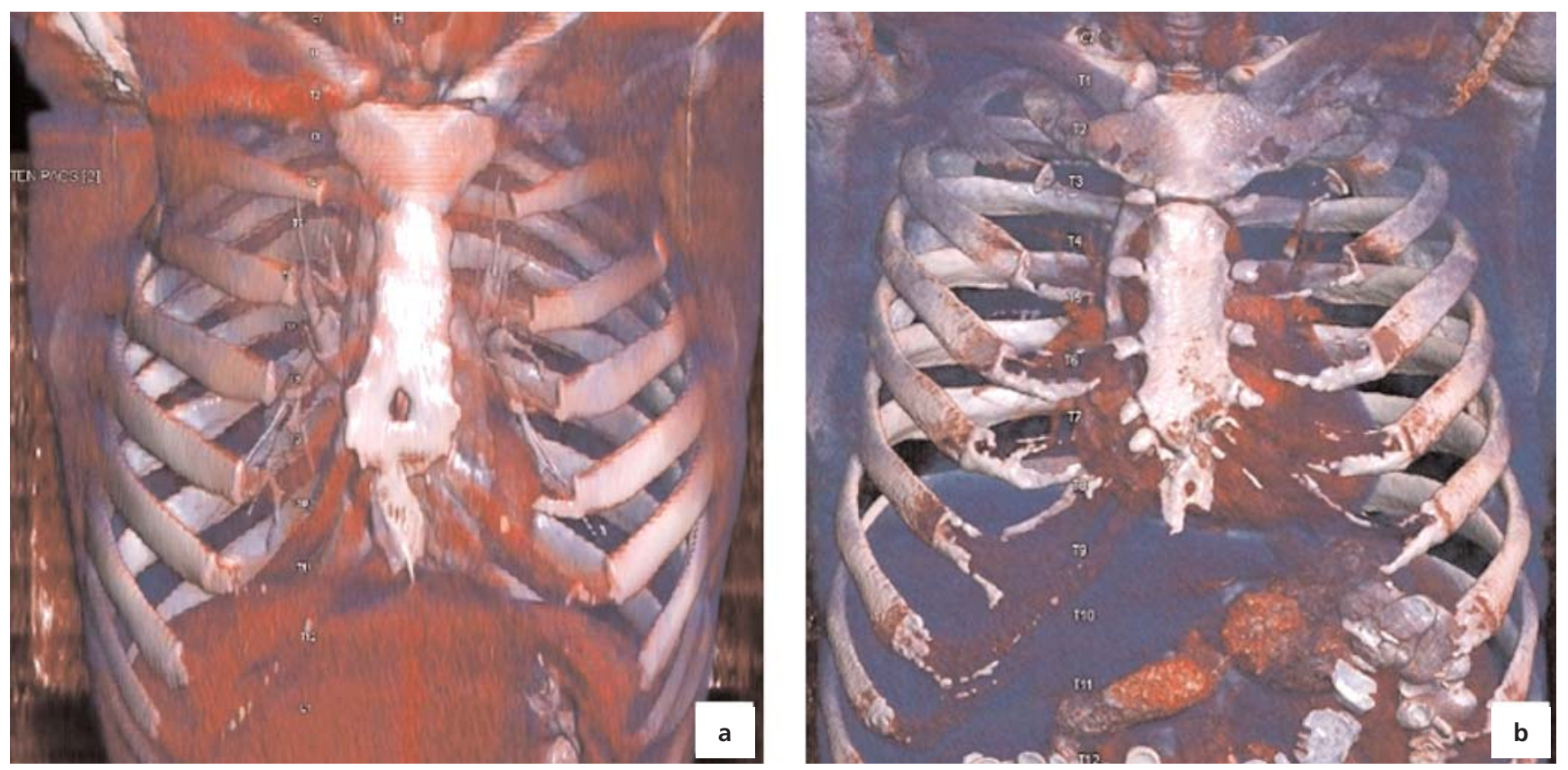

Figure 5. Foramina detected with MDCT (a) foramen on body of sternum; (b) foramen on the xiphoid process. 

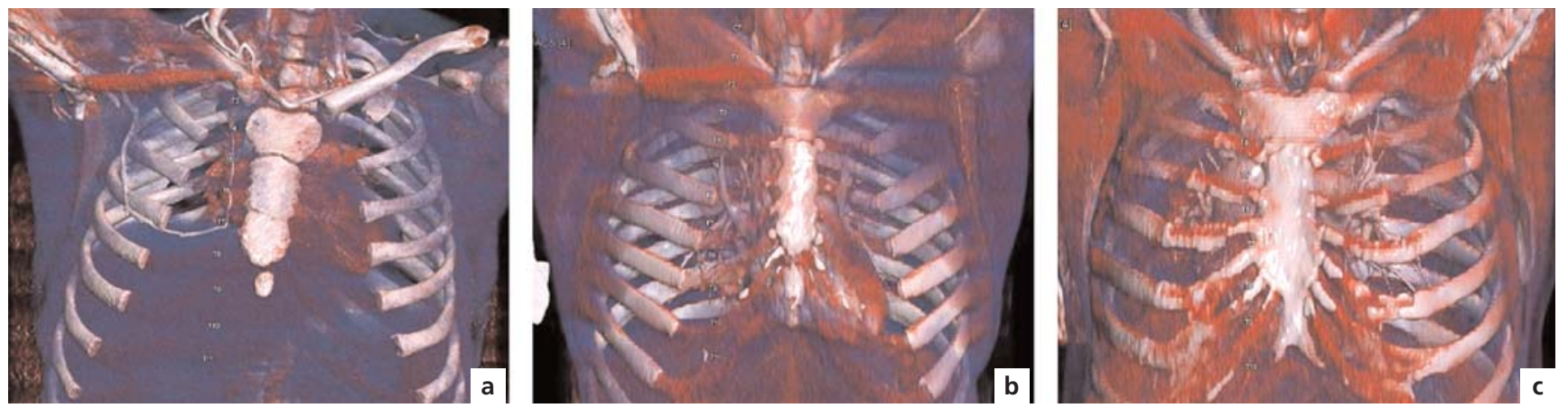

Figure 6. Degree of ossification between the parts of the sternum as detected with MDCT. (a) No ossification (Type1); (b) partial ossification (Type2); (c) complete ossification (Type 3).

Table 2

MW measurements according to age groups.

\begin{tabular}{|c|c|c|c|c|}
\hline & Group & Mean \pm SD & p & $\begin{array}{l}\text { Differences according } \\
\text { to } p \text {-value }\end{array}$ \\
\hline \multirow[t]{9}{*}{ MW } & $0-9$ & $2.68 \pm 0.8 \mathrm{~cm}$ & 0.000 & $2>1$ \\
\hline & 10-19 & $4.78 \pm 0.75 \mathrm{~cm}$ & & $3>1$ \\
\hline & $20-29$ & $5.06 \pm 0.74 \mathrm{~cm}$ & & $4>1$ \\
\hline & $30-39$ & $5.24 \pm 0.78 \mathrm{~cm}$ & & $5>1$ \\
\hline & $40-49$ & $5.19 \pm 0.69 \mathrm{~cm}$ & & $6>1$ \\
\hline & $50-59$ & $5.18 \pm 0.82 \mathrm{~cm}$ & & $7>1$ \\
\hline & \multirow{3}{*}{$\geq 60$} & & & $5>2$ \\
\hline & & $5.35 \pm 0.84 \mathrm{~cm}$ & & $7>2$ \\
\hline & & & & $7>3$ \\
\hline
\end{tabular}

CW2 was significantly higher in $\geq 60$ and lower in the 0-9 age group for both genders. Those in the 10-19 age group had significantly higher CW2 values than the $0-9$ age group. CW2 of other age groups was significantly higher than $0-9$ and $10-19$ age groups $(\mathrm{p}<0.05)$ (Tables 5 and 6).

Table 4

$\mathrm{CL}$ measurements according to age groups.

\begin{tabular}{ccccc} 
& Group & Mean \pm SD & $\mathbf{p}$ & $\begin{array}{c}\text { Differences according } \\
\text { to } \mathbf{p} \text {-value }\end{array}$ \\
\hline $\mathrm{CL}$ & $0-9$ & $4.48 \pm 1.29 \mathrm{~cm}$ & 0.000 & $2>1$ \\
& $10-19$ & $8.32 \pm 1.3 \mathrm{~cm}$ & $3>1$ \\
$20-29$ & $9.12 \pm 1.6 \mathrm{~cm}$ & $4>1$ \\
$30-39$ & $9.36 \pm 1.28 \mathrm{~cm}$ & $5>1$ \\
$40-49$ & $8.8 \pm 1.43 \mathrm{~cm}$ & $6>1$ \\
$50-59$ & $9.13 \pm 1.5 \mathrm{~cm}$ & $7>1$ \\
\hline \multirow{2}{*}{20} & $9.16 \pm 1.47 \mathrm{~cm}$ & $4>2$ \\
& & $7>2$ \\
\hline
\end{tabular}

Table 3

ML measurements according to age groups.

\begin{tabular}{|c|c|c|c|c|}
\hline & Group & Mean \pm SD & p & $\begin{array}{l}\text { Differences according } \\
\text { to } p \text {-value }\end{array}$ \\
\hline \multirow[t]{11}{*}{ ML } & $0-9$ & $2.49 \pm 0.55 \mathrm{~cm}$ & 0.000 & $2>1$ \\
\hline & 10-19 & $4.22 \pm 0.59 \mathrm{~cm}$ & & $3>1$ \\
\hline & $20-29$ & $4.6 \pm 0.5 \mathrm{~cm}$ & & $4>1$ \\
\hline & $30-39$ & $4.6 \pm 0.6 \mathrm{~cm}$ & & $5>1$ \\
\hline & $40-49$ & $4.69 \pm 0.65 \mathrm{~cm}$ & & $6>1$ \\
\hline & 50-59 & $4.56 \pm 0.52 \mathrm{~cm}$ & & $7>1$ \\
\hline & \multirow{5}{*}{$\geq 60$} & \multirow{5}{*}{$4.70 \pm 0.65 \mathrm{~cm}$} & & $3>2$ \\
\hline & & & & $4>2$ \\
\hline & & & & $5>2$ \\
\hline & & & & $7>2$ \\
\hline & & & & $5>6$ \\
\hline
\end{tabular}

The angle of Louis (LA) was 158.820. LA showed no statistically significant difference among genders $(\mathrm{p}>0.05)$. LA was significantly higher in $\geq 60$ and lower in the $0-9$

Table 5

CW1 measurements according to age groups.

\begin{tabular}{|c|c|c|c|c|}
\hline & Group & Mean \pm SD & p & $\begin{array}{c}\text { Differences according } \\
\text { to } p \text {-value }\end{array}$ \\
\hline \multirow[t]{10}{*}{ CW1 } & $0-9$ & $1.48 \pm 0.42 \mathrm{~cm}$ & 0.000 & $2>1$ \\
\hline & 10-19 & $2.5 \pm 0.46 \mathrm{~cm}$ & & $3>1$ \\
\hline & $20-29$ & $2.6 \pm 0.5 \mathrm{~cm}$ & & $4>1$ \\
\hline & $30-39$ & $2.75 \pm 0.5 \mathrm{~cm}$ & & $5>1$ \\
\hline & $40-49$ & $2.73 \pm 0.57 \mathrm{~cm}$ & & $6>1$ \\
\hline & $50-59$ & $2.75 \pm 0.49 \mathrm{~cm}$ & & $7>1$ \\
\hline & \multirow{4}{*}{$\geq 60$} & \multirow{4}{*}{$2.87 \pm 0.54 \mathrm{~cm}$} & & $5>2$ \\
\hline & & & & $7>2$ \\
\hline & & & & $7>3$ \\
\hline & & & & $7>4$ \\
\hline
\end{tabular}


Table 6

CW2 measurements according to age groups.

\begin{tabular}{ccccc} 
& Group & Mean \pm SD & $\mathbf{p}$ & $\begin{array}{c}\text { Differences according } \\
\text { to } \mathbf{p} \text {-value }\end{array}$ \\
\hline CW2 & $0-9$ & $1.59 \pm 0.52 \mathrm{~cm}$ & 0.000 & $2>1$ \\
& $10-19$ & $3.03 \pm 0.67 \mathrm{~cm}$ & $3>1$ \\
$20-29$ & $3.34 \pm 0.59 \mathrm{~cm}$ & $4>1$ \\
$30-39$ & $3.34 \pm 0.69 \mathrm{~cm}$ & $5>1$ \\
$40-49$ & $3.39 \pm 0.87 \mathrm{~cm}$ & $6>1$ \\
$50-59$ & $3.35 \pm 0.65 \mathrm{~cm}$ & $7>1$ \\
\hline & & $5>2$ \\
& & $7>2$ \\
& & & $5>4$ \\
\end{tabular}

age group for both genders $(\mathrm{p}<0.05)$. LA of other age groups was significantly higher than $0-9$ and $10-19$ age groups $(\mathrm{p}<0.05)$ (Table 7).

Examination of the xiphoid process according to its shape revelaed 335 (48\%) cases as Type 1, $316(43 \%)$ as Type 2 and $49(7 \%)$ as the Type 3 . The direction of the xiphoid process was in line with the body in $536(77 \%)$ cases and having a slope towards the ventral direction in $164(24 \%)$ cases. At least 1 foramen was observed in xiphoid process in $81(12 \%)$ cases, and in the body of sternum in $36(5 \%)$ cases. Considering the xiphoid process variations, the number of xiphoid processes with
Table 7

LA measurements according to age groups.

\begin{tabular}{|c|c|c|c|c|c|}
\hline & Group & Mean \pm SD & $\begin{array}{c}p \\
\text { (Females) }\end{array}$ & $\begin{array}{c}\mathbf{p} \\
\text { (Males) }\end{array}$ & $\begin{array}{l}\text { Differences } \\
\text { according } \\
\text { to } p \text {-value }\end{array}$ \\
\hline \multirow[t]{11}{*}{ LA } & $0-9$ & $162.49 \pm 8.0 \mathrm{~cm}$ & 0.131 & 0.000 & $2>1$ \\
\hline & 10-19 & $160.77 \pm 5.851 \mathrm{~cm}$ & & & $3>1$ \\
\hline & $20-29$ & $158.7 \pm 6.983 \mathrm{~cm}$ & & & $4>1$ \\
\hline & $30-39$ & $158.49 \pm 6.736 \mathrm{~cm}$ & & & $5>1$ \\
\hline & $40-49$ & $157.78 \pm 7.425 \mathrm{~cm}$ & & & $6>1$ \\
\hline & $50-59$ & $157.43 \pm 7.464 \mathrm{~cm}$ & & & $7>1$ \\
\hline & & & & & $3>2$ \\
\hline & & & & & $5>2$ \\
\hline & $\geq 60$ & $156.49 \pm 8.0 \mathrm{~cm}$ & & & $6>2$ \\
\hline & & & & & $7>2$ \\
\hline & & & & & $5>4$ \\
\hline
\end{tabular}

a single foramen was $61(75 \%)$, the number of xiphoid processes with two foramina was 15 (18\%), and the number of xiphoid processes with more than two foramina was $6(7 \%)$. The number of corpus containing a single foramen was 34 , and the number of corpus containing two foramina was 2 .

The ossification rates among different groups showed that the highest ossification was present in 30-39 age group, partial ossification was highest in 20-29 age group, and no ossification in 0-9 age group as expected (Figures 7-9).

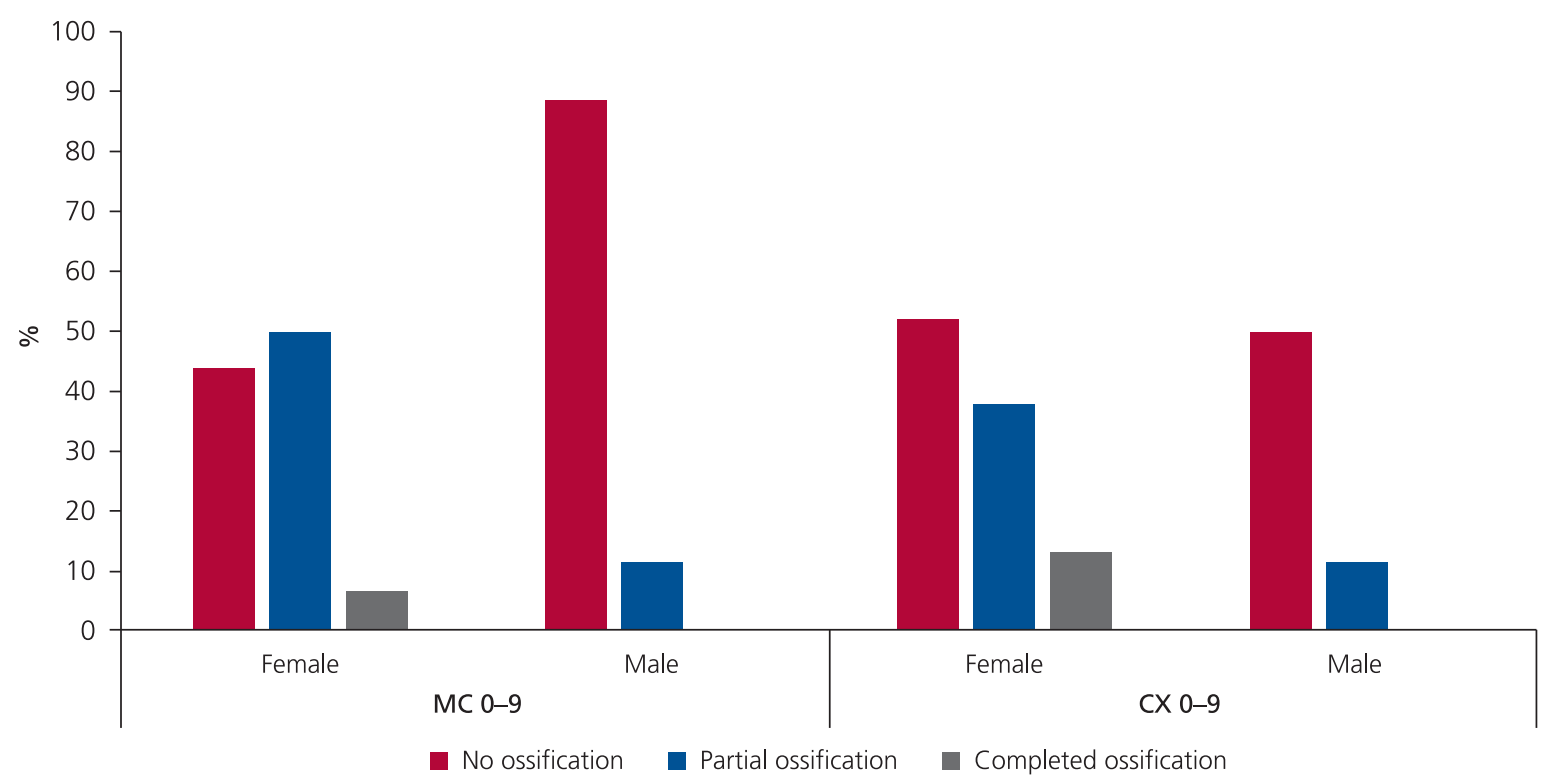

Figure 7. Degree of ossification in the 0-9 age group. CX: ossification between body of the sternum and the xiphoid process; MC: ossification between manubrium and body of the sternum. 


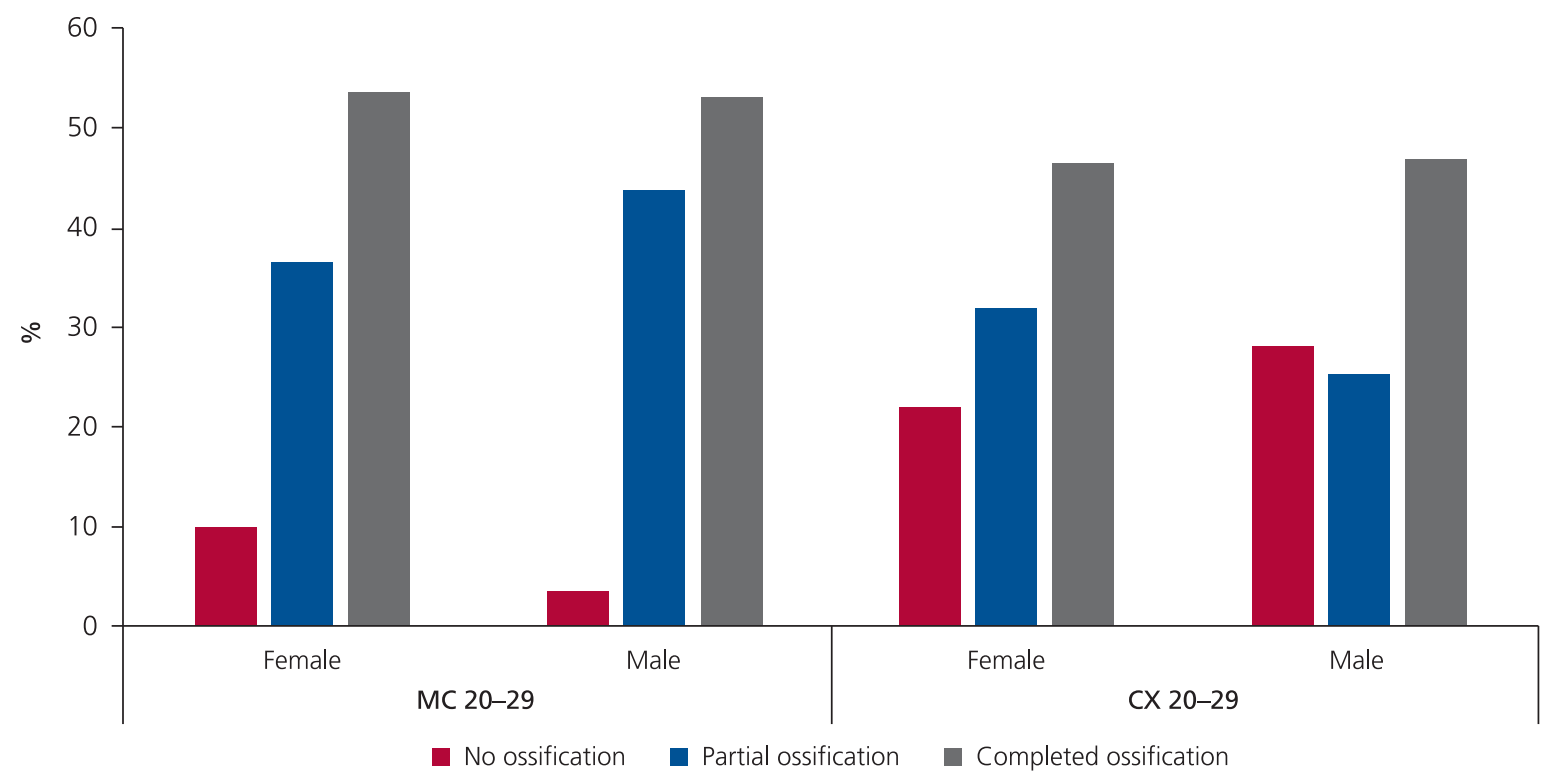

Figure 8. Degree of ossification in the 10-19 age group. CX: ossification between body of the sternum and the xiphoid process; MC: ossification between manubrium and body of the sternum.

\section{Discussion}

Three-dimensional radiological studies are gold standart to understand the anatomy and relations of the bony tissue such as sternum. The MDCT images cover larger anatomical regions and it makes bone measurements very close to real values. ${ }^{[2,10]}$ There are limited mumber of studies examining the morphology and the variations of ster- num with MDCT. ${ }^{[1]}$ So this study relied on measurements taken with MDCT.

Determination of gender from skeleton is of utmost importance in forensic medicine and anthropology. ${ }^{[12]}$ It is challenging to estimate sex and age from bones that have been disintegrated for various reasons. Data collected from a single bone is therefore important for gender predic-

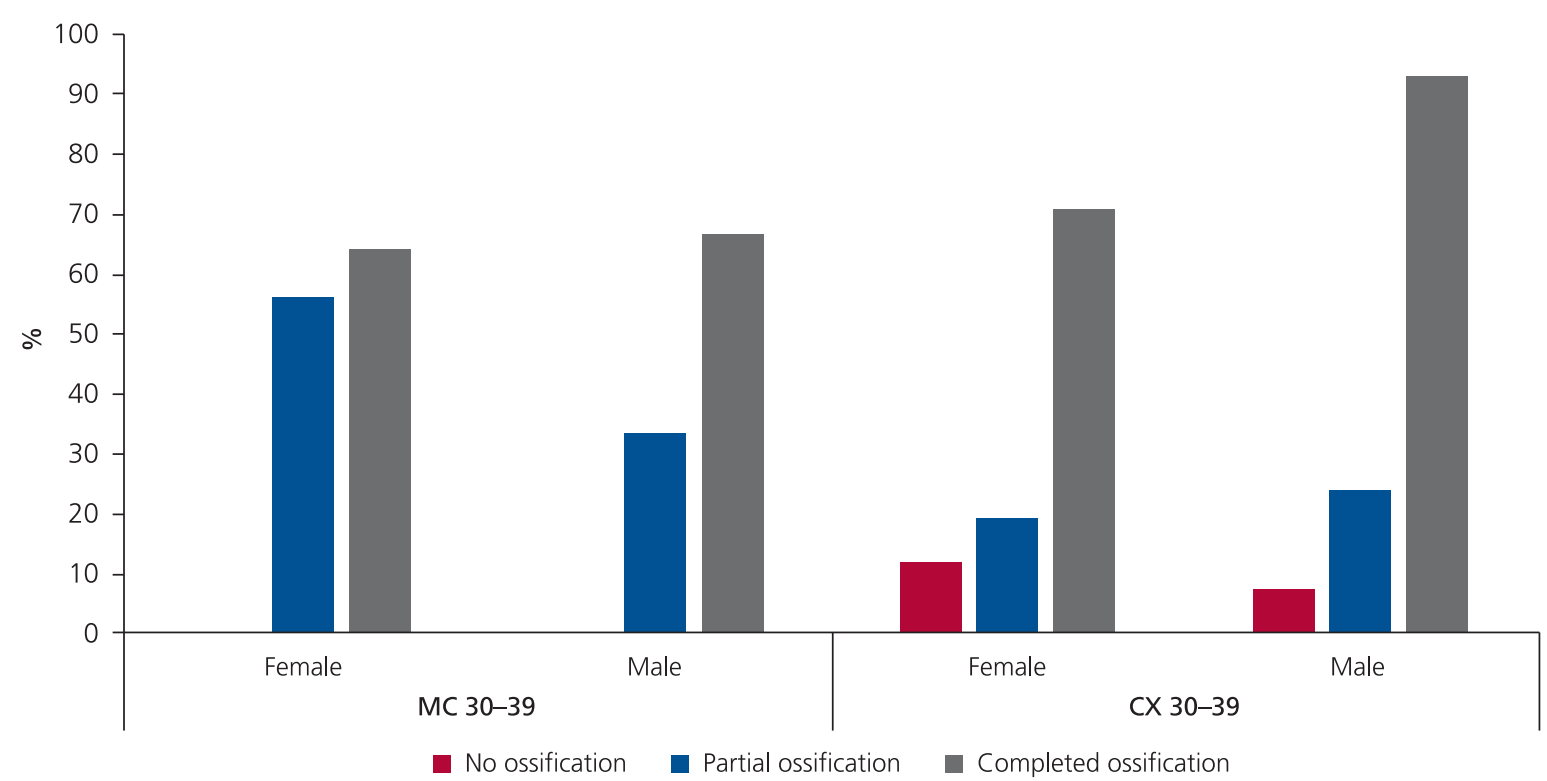

Figure 9. Degree of ossification in the 20-29 age group. CX: ossification between body of the sternum and the xiphoid process; MC: ossification between manubrium and body of the sternum. 
Table 8

Typing the xiphoid process according to its shape and direction in previously published studies.

\begin{tabular}{|c|c|c|c|c|c|c|}
\hline & & \multicolumn{3}{|c|}{ Xiphoid process shape } & \multicolumn{2}{|c|}{ Xiphoid process direction } \\
\hline & & Type 1 & Type 2 & Type 3 & Type1 & Type2 \\
\hline Kirum et al. ${ }^{[29]}$ (2017) & Dry bone & $42.9 \%$ & $57.1 \%$ & & & \\
\hline Yekeler et al. ${ }^{[7]}$ (2006) & MDCT & $27.2 \%$ & $71 \%$ & $0.7 \%$ & & \\
\hline Akın et al. ${ }^{[9]}(2011)$ & $\mathrm{MDCT}$ & $32.8 \%$ & $62.6 \%$ & $4.6 \%$ & $65.4 \%$ & $33.2 \%$ \\
\hline Present study & MDCT & $47.9 \%$ & $45.1 \%$ & $7 \%$ & $77 \%$ & $24 \%$ \\
\hline
\end{tabular}

tion. ${ }^{[13,14]}$ Owing to its big size, sternum is not destroyed very quickly and can be scanned easily, thus it can be used in gender and age determinations. ${ }^{[14,15]}$

The studies on sternum measurements generally reports gender difference. ${ }^{[11,16,17]}$ But there are differences of opinion about whether to determine gender or not. ${ }^{[15,18-20]}$ Recent studies have shown that the sternum is longer, wider and thicker in the males. ${ }^{[16,17,21]}$ The results of our study showed that the width and the length of the manubrium was significantly higher in males than that of females, so that gender determination can be made by using sternum.

The width (MW) and the length (ML) of manubrium was reported to be significantly higher in males than females $^{[14,18,19,21-26]}$ as our results. $M W$ and ML was not examined according to age groups previously. Our results showed the MW and ML as increasing rapidly and significantly until the age of 10-19 and then increasing gradually at later ages without making a significant difference. Thus, together with other measurements, MW and ML can be used for age estimation as well.

The size of the body of sternum was also found larger in males than that of females ${ }^{[11,20,21,25,26]}$ as in our study. It is known that gender can be determined by using the length and the width of manubrium and body of sternum as landmarks. ${ }^{[21,25,27,28]}$ However, no data is available regarding the size of the body of sternum in different age groups. As MW and ML, the results of our study showed that the size of the sternum (CL, CW1, CW2) increased rapidly until the age of 10-19. Thus, we suggest that age determination can be made in addition to gender by using the CL, CW1, CW2 as references.

The angle of Louis (LA) has previously not recommended for gender discrimination. ${ }^{[2,30]}$ According to the results of this study, LA showed no statistically significant difference among genders as well.

Previous studies done on typing the xiphoid process according to its shape showed that the incidence changes in a wide range as; Type 1 varying between $27.2 \%$ and
42.9\%, Type 2 between $45.1 \%$ and $71 \%$, and Type 3 between $0.7 \%$ and $4.6 \%$ (Table 8). ${ }^{[7,9,29]}$ The most frequent type was as detected as Type 1 (47.9\%), followed by Type $2(45.1 \%)$ and least common Type 3 (7\%).

Sternal fractures account for about $5-10 \%$ of all thoracic injuries. It is an injury that occurs directly with the steering wheel or seat belt. It can also occur during cardiopulmonary resuscitation. Differences in xiphoid direction can also be misidentified as a fracture. So, it is important to know the variations in the shape and direction of the xiphoid process. ${ }^{[17,27]}$ In a study on determining the direction of the xiphoid process, it had a ventrally directed slope in $65.4 \%$ (Type 1) and in line with the body in $33.2 \%$ (Type 2) (Table 8). ${ }^{[9]} 77 \%$ of our cases was Type 1 , and $24 \%$ was Type 2.

The frequency of foramina on the sternum have been investigated in various studies. The presence of any foramen on the xiphoid process was reported in a great range between $9.5 \%$ to $36.1 \%$ (Table 9). ${ }^{[7,9,29,31]}$ A foramen on the xiphoid process was observed in $11.7 \%$ of our cases, $75 \%$ of which were in the form of a single foramen. In $18 \%$ of our cases there were two foramina and $7 \%$ more than two foramina. The body of sternum was reported to have fewer foramina, the incidence being $4.3 \%$ to $16.6 \%$ (Table 9). ${ }^{[7,929,31-34]}$ Our series showed a single foramen in the body

Table 9

Foramen ratios on xiphoid process in previously published studies.

\begin{tabular}{llcc} 
& & $\begin{array}{c}\text { Presence of } \\
\text { foramen on the } \\
\text { xiphoid process }\end{array}$ & $\begin{array}{c}\text { Presence of } \\
\text { foramen on the } \\
\text { sternum body }\end{array}$ \\
\hline Yekeler et al. ${ }^{[7]}(2006)$ & MDCT & $27.4 \%$ & $4.5 \%$ \\
Kirum et al. ${ }^{[29]}(2017)$ & Dry bone & $9.5 \%$ & $12.9 \%$ \\
Babinski et al. ${ }^{[31]}(2015)$ & MDCT & $17.5 \%$ & $16.6 \%$ \\
Akin et al. ${ }^{[9]}(2011)$ & MDCT & $36.1 \%$ & \\
Singh et al. ${ }^{[32]}(2013)$ & Cadaver & & $11.9 \%$ \\
Stark at al. ${ }^{[1]}(1986)$ & CT & & $4.3 \%$ \\
Moore et al. ${ }^{[34]}(2015)$ & CT & & $6.6 \%$ \\
Present study & MDCT & $11.7 \%$ & $\% 5.1$ \\
\hline
\end{tabular}


of sternum in $5.1 \%$ of the cases. The presence of foramina on the sternum was associated with some fatal complications in early infancy. ${ }^{[35-37]}$ During sternal puncture or sternal bone marrow aspiration, a sternal foramen may pose a great danger due to unwanted cardiac or major vascular damage. ${ }^{[7,36,38]}$ Therefore, knowing the presence and the frequency of foramina is clinically important.

The ossification of the sternum had been reported to complete in various ages. Pekcan ${ }^{[39]}$ stated that ossification between the manubrium and corpus was completed at the age of 31 in men and 26 in women, Garg et al. ${ }^{[40]}$ found that full ossification between the manubrium and the corpus was still not completed in $60 \%$ of cases in the $60-65$ age group. In the study of Kaneriye et al., ${ }^{[41]}$ no ossification was observed under the age of 40 . In another study, the ossification between the manubrium and the corpus started at the age of 40 was completed at the age of 55, and the ossification between the xiphoid process and corpus was completed at $50 .{ }^{[22]}$ It is known that manubrium and corpus can remain united and amount of union increases with advancing age. ${ }^{[42]}$ Since the manubriosternal joint has a fibrocartilage, even if the ossification gets completed, the cartilage structure is preserved inside the joint. In our study, there were no significant gender differences for ossification between the manubrium and corpus, which started at the ages of 0-9 and completed between the ages of 30-39. The ossification between the xiphoid process and the corpus started at the ages of $0-9$, completed at the ages of 50-59 and there was no significant gender difference.

There are some limitations in our study. This is a retrospective study and since all images were obtained in the supine position, personal characteristics such as height, weight, presence of anatomical deformities or postural disorders could not be identified. For this reason, we think that it would be beneficial to support it with prospective studies taking into consideration of other parameters such as height, weight, thoracic diameter, BMI of the cases in different positions (standing vs sitting).

\section{Conclusion}

Data collected from a single bone is important for age and sex prediction especially in forensic medicine. These data taken from a large series containing 700 images may also contribute to evaluation of variations in sternal morphology by age and gender. We suggest that the results obtained from our study may contribute basic anatomy knowledge and be used by thoracic surgeons and radiologists.

\section{Author Contributions}

GB: data collection and data analysis, writing text. NUD: Project development, data analysis, final check of the manuscript. MK: data collection and analysis. ZF: project development, final check of the manuscript. AKK: project development, final check of the manuscript

\section{References}

1. Stark P, Jaramillo D. CT of the sternum. AJR Am J Roentgenol 1986;147:72-7.

2. Weaver AA, Schoell SL, Nguyen CM, Lynch SK, Stitzel JD. Morphometric analysis of variation in the sternum with sex and age. J Morphol 2014;275:1284-99.

3. Franklin D, O'Higgins P, Oxnard CE, Dadour I. Determination of sex in south african blacks by discriminant function analysis of mandibular linear dimensions : a preliminary investigation using the zulu local population. Forensic Sci Med Pathol 2006;2:263-8.

4. Akhlaghi M, Moradi B, Hajibeygi M. Sex determination using anthropometric dimensions of the clavicle in Iranian population. J Forensic Leg Med 2012;19:381-5.

5. Akhlaghi M, Sheikhazadi A, Ebrahimnia A, Hedayati M, Nazparvar B, Saberi Anary SH. The value of radius bone in prediction of sex and height in the Iranian population. J Forensic Leg Med May 2012;19:219-22.

6. Saraf A, Kanchan T, Krishan K, Ateriya N, Setia P. Estimation of stature from sternum - exploring the quadratic models. J Forensic Leg Med 2018;58:9-13.

7. Yekeler E, Tunaci M, Tunaci A, Dursun M, Acunas G. Frequency of sternal variations and anomalies evaluated by MDCT. AJR Am J Roentgenol 2006;186:956-60.

8. Bayarogullari H, Yengil E, Davran R, Aglagul E, Karazincir S, Balci A. Evaluation of the postnatal development of the sternum and sternal variations using multidetector CT. Diagn Interv Radiol 2014;20:82-9.

9. Akin K, Kosehan D, Topcu A, Koktener A. Anatomic evaluation of the xiphoid process with 64-row multidetector computed tomography. Skeletal Radiol 2011;40:447-52.

10. Gayzik FS, Yu MM, Danelson KA, Slice DE, Stitzel JD. Quantification of age-related shape change of the human rib cage through geometric morphometrics. J Biomech 2008;41:1545-54.

11. Oner Z, Turan MK, Oner S, Secgin Y, Sahin B. Sex estimation using sternum part lenghts by means of artificial neural networks. Forensic Sci Int 2019;301:6-11

12. Scheuer L. Application of osteology to forensic medicine. Clin Anat 2002;15:297-312.

13. Morgan O, Tidball-Binz M, vanAlphen D (eds). Management of dead bodies after disasters: a field manual for first responders. Washington, DC: Pan American Health Organization; 2006. [Internet]. Available from: https://www.icrc.org/en/doc/assets/files/ other/icrc_002_0880.pdf

14. Sidler M, Jackowski C, Dirnhofer R, Vock P, Thali M. Use of multislice computed tomography in disaster victim identification advantages and limitations. Forensic Sci Int 2007;169:118-28.

15. Peleg S, Kallevag RP, Dar G, Steinberg N, Masharawi Y, May H. New methods for sex estimation using sternum and rib morphology. Int J Legal Med 2020;134:1519-30. 
16. Torwalt CRMM, Hoppa RD. A test of sex determination from measurements of chest radiographs. J Forensic Sci 2005;50:785-90.

17. Selthofer R, Nikolic V, Mrcela T. Morphometric analysis of the sternum. Coll Antropol 2006;30:43-7.

18. Jit I, Jhingan V, Kulkarni M. Sexing the human sternum. Am J Phys Anthropol 1980;53:217-24.

19. Franklin D, Flavel A, Kuliukas A, Cardini A, Marks MK, Oxnard C, O'Higgins P. Estimation of sex from sternal measurements in a Western Australian population. Forensic Sci Int 2012;217:230.e1-5.

20. Torimitsu S, Makino Y, Saitoh H. Estimation of sex in Japanese cadavers based on sternal measurements using multidetector computed tomography. Leg Med (Tokyo) 2015;17:226-31.

21. Bongiovanni R, Spradley MK. Estimating sex of the human skeleton based on metrics of the sternum. Forensic Sci Int 2012;219:290.e1-7.

22. Gautam RS, Shah GV, Jadav HR, Gohil BJ. The human sternum as an index of age \& sex. J Anat Soc India 2003;52:22-3.

23. Ekizoglu O, Hocaoglu E, Inci E. Sex estimation from sternal measurements using multidetector computed tomography. Medicine (Baltimore) 2014;93:e240.

24. Macaluso PJ. The efficacy of sternal measurements for sex estimation in South African blacks. Forensic Sci Int 2010;202:111.e1-7.

25. Osunwoke EA, Gwunireama IU, Orish CN, Ordu KS, Ebowe I. A study of sexual dimorphism of the human sternum in the southern Nigerian population Journal of Applied Biosciences 2010;26:16369.

26. Ramadan SU, Türkmen M, Dolgun N. Sex determination from measurements of the sternum and fourth rib using multislice computed tomography of the chest. Forensic Sci Int 2010;15:120.e1-3.

27. Hunnargi SA, Menezes RG, Kanchan T. Sexual dimorphism of the human sternum in a Maharashtrian population of India: a morphometric analysis. Leg Med (Tokyo) 2008;10:6-10.

28. Manoharan C, Jeyasingh T, Dhanalakshmi V, Thangam D. Is human sternum a tool for determination of sex. Indian Journal of Forensic and Community Medicine 2016;3:60-3.

29. Kirum GG, Munabi IG, Kukiriza J. Anatomical variations of the sternal angle and anomalies of adult human sterna from the Galloway osteological collection at Makerere University Anatomy Department. Folia Morphol (Warsz) 2017;76:689-94.

ORCID ID:

G. Bolatlı 0000-0002-7648-0237; N. Ünver Doğan 0000-0001-5696-5547: M. Koplay 000-0001-7513-4968; Z. Fazlığulları 0000-0002-5103-090X; A. K. Karabulut 0000-0002-9635-8829
30. Standring S (ed). Gray's anatomy: The anatomical basis of clinical practice. 40th ed. London: Churchill Livingstone Elsevier; 2016. p. 136.

31. Babinski MA, de Lemos L, Babinski MSD, Goncalves MVT, De Paula RC, Fernandes RMP. Frequency of sternal foramen evaluated by MDCT: a minor variation of great relevance. Surg Radiol Anat 2015;37:287-91.

32. Singh J, Pathak RK. Sex and age related non-metric variation of the human sternum in a Northwest Indian postmortem sample: a pilot study. Forensic Sci Int 2013;228:181.e1-12.

33. Stark P. Midline sternal foramen: CT demonstration. J Comput Assist Tomogr 1985;9:489-90.

34. Moore MK, Stewart JH, McCormick WF. Anomalies of the human chest plate area. Radiographic findings in a large autopsy population. Am J Forensic Med Pathol 1988;9:348-54.

35. Wolochow M. Fatal cardiac tamponade through congenital sternal foramen. Lancet 1995;346:442.

36. Bhootra BL. Fatality following a sternal bone marrow aspiration procedure: a case report. Med Sci Law 2004:44:170-2.

37. Halvorsen TB, Anda SS, Naess AB, Levang OW. Fatal cardiac tamponade after acupuncture through congenital sternal foramen. Lancet 1995;345:1175.

38. Pascali VL, Lazzaro P, Fiori A. Is sternal bone-marrow needle-biopsy still a hazardous technique - report of 3 further fatal cases. Am J Foren Med Path 1987;8:42-4.

39. Pekcan M. Age and gender determination according to the degree of fusion of the sternum and segments with multislice CT imaging. Dissertation, Istanbul: Istanbul Medical Faculty, Radiodiagnostics Department; 2014. p. 62-3. [Internet]. Available from: http://acikerisim.istanbul.edu.tr/bitstream/handle/123456789/24513/52780.pd f? sequence $=1$.

40. Garg A, Goyal N, Gorea R, Bharwa J. Radiological age estimation from manubrio-sternal joint in living population of Punjab. Journal of Punjab Academy of Forensic Medicine and Toxicology 2011;11: 69-71.

41. Kaneriya D, Umarvanshi B, Patil D, Mehta C, Chauhan K, Vora R. Age determination from fusion of the sternal elements. International Journal of Basic and Applied Medical Sciences 2013;3:22-9.

42. Chandrakanth HV, Kanchan T, Krishan K, Arun M, Pramod Kumar GN. Estimation of age from human sternum: an autopsy study on a sample from South India. Int J Legal Med 2012;126:863-8.

Correspondence to: Güneş Bolatlı, PhD

Department of Anatomy, School of Medicine,

Siirt University, Siirt, Turkey

Phone: +90 5057611324

e-mail: gunesbolatli83@gmail.com

Conflict of interest statement: No conflicts declared.

This is an open access article distributed under the terms of the Creative Commons Attribution-NonCommercial-NoDerivs 3.0 Unported (CC BY-NCND3.0) Licence (http://creativecommons.org/licenses/by-nc-nd/3.0/) which permits unrestricted noncommercial use, distribution, and reproduction in any medium, provided the original work is properly cited. Please cite this article as: Bolatlı G, Ünver Doğan N, Koplay M, Fazlığulları Z, Karabulut AK. Evaluation of sternal morphology according to age and sex with multidetector computerized tomography. Anatomy 2020;14(1):29-38. 